\section{Message from the Muscle Study Group Chair}

Richard J. Barohn, MD

Once again, this year the Muscle Study Group (MSG) meeting will be virtual and will be held October 1- 3. We initially had planned to do this year in-person in Georgetown, but the hotel/convention center on the Georgetown University campus was not ready to take routine guests and meetings as they are still in Covid-19 mode. We looked at other in-person options but for this year it seems virtual was the best option. Last year our virtual meeting was fantastic and I am sure this year's will be as well. I know it is heresy to claim to like virtual better than in-person meetings, but I do! The biggest downside is for the junior investigators and students. They need face to face time to meet others in the field and that is the biggest part that is missing with virtual meetings.

Nevertheless, we have an outstanding meeting planned, and in this issue of the RRNMF Neuromuscular Journal we are publishing the abstracts, agenda, and announcements from our sponsors ahead of the meeting. We received abstracts from many investigators and universities, some in which the first authors were students or junior faculty, and others with very senior faculty taking the lead. I am very excited about the breadth of new information that will be transmitted at this meeting.

In addition, we offered to all our sponsors that they could also submit abstracts and many of them did. I think this is an essential unique aspect to the MSG meetings which we particularly have been promoting in recent years. We want our industry sponsors to interact very closely with our investigators and clinicians at our university campuses. For clinical translational science to advance we both need each other very much. We want to maximize the ways we can interact together in true scientific forums. While the MSG is growing, it is still intimate enough that these interactions can be very productive and meaningful. The most advanced, cutting-edge therapies often begin at the university level in pre-clinical laboratories, then move to industry to get them into clinical trials, which is where the clinical scientists are needed to give industry input on trial design, patient recruitment and so much more. And, of course, the industry trials are then done at our sites. So the interaction and partnership are essential, but it is better to have the conversation all along the spectrum and the MSG is such a forum. We have invited many of the industry presenters to also submit full length papers to the RRNMF Neuromuscular Journal and we hope to see some of these come out in the next one or two journal issues after peer review.
Also, we encourage all the academic groups presenting information to put their presentations into a full article format and submit it to the RRNMF Neuromuscular Journal in the near future. I am pleased to tell you all that earlier this year after the successful use of this journal for last year's meeting, the Executive Committee of the MSG approved my resolution to have the RRNMF Neuromuscular Journal as the official journal of our organization.

Once again, rather than having typical (or atypical) virtual "poster" sessions (which I think is difficult to pull off virtually), we are asking each presenter to give a "FLASH !" 5 minute presentation with 5 minutes of question and answer. This went well last year and I like the speed of this presentation format. This also allows us to get more presentations into the program. So FLASH speakers: please be very fast! And not many slides - five or six maximum! As usual, at each MSG meeting we have asked leaders in the field to give talks on their area of specialization.

We have many outstanding speakers. These talks are twenty minutes each. Each year we select the Robert C. Griggs Annual Meeting Lecture and we are very pleased to have Professor Gordon Smith, Chairman of Neurology at Virginia Commonwealth University to give this keynote address. Dr. Smith will have about fifty minutes to do the keynote address with ten more minutes for question and answer. Last year we inaugurated the "Shark Tank" session in which several MSG members "pitched" their research idea to a panel of neuromuscular judges. The winner receives a $\$ 10,000$ grant to do the project they pitched. We have three worthy competitors again this year. We will hear from our MSG funded research fellows about the fascinating work they are doing or will do during their twoyear fellowships which are jointly sponsored with the AAN/ American Brain Foundation. This year two of our fellows will be presenting their work: Paloma Gonzalez-Perez, M.D. (Massachusetts General Hospital) and Renatta Knox, M.D. (Nationwide Children's Hospital). To support all that the MSG does during the meeting and throughout the year we are very happy to have so many industry sponsors who are eager to be part of this exciting event. This year we have given these sponsors space to place information about their company in the program and thus in this issue of the RRNMF Neuromuscular Journal. So please join us for the 2021 MSG meeting October 1-3. If you have not registered, it is not too late. You can register at: Musclestudygroup. org/events/2021-muscle-study-group-annual-scientificmeeting/.

I would like to thank, as always, Professor Michael Hanna, the Co-Chair of the MSG and the Director of the University College London Institute of Neurology for his steady support over the years. This year our Program Planning Committee again did an amazing job choosing and asking our speakers to be part of the program and they expertly arranged all the details of the three-day agenda. 
2021 program planning committee:

Chafic Karam, MD (University of Pennsylvania Health System) - Chair

James Lilleker, MBChB, PhD (University of

Manchester) - Co-Chair

Senda Ajroud-Driss, MD (Northwestern University)

Laurie Gutmann, MD (Indiana University)

Melissa McIntyre, DPT (University of Utah)

Colin Quinn, MD (University of Pennsylvania Health System)

Tracey Willis, MBChB, MMedSci, MD (Chester University, UK)

Amelia Wilson, DPT (University of Utah Health Science Center)

2021 Shark Tank Panel:

James Lilleker, MBChB, PhD

Dave Arnold, MD

Tracey Willis, MBChB, MMedSci, MD

Gita Ramdharry, DPT

The Executive Committee for the MSG which approves the planning committees and plan all that the MSG does is:

Myself and Mike Hanna, MD as Chair and Co-Chair

Robert C. Griggs, MD (Chair Emeritus)

William David, MD (Massachusetts General Hospital)

Michael Hehir, MD (University of Vermont Medical

Center)

Valeria Sansone, MD (NEMO Clinical Center)

Melissa McIntyre, DPT (University of Utah Health Science Center)

Michael McDermott, PhD (Statistician - University of Rochester Medical Center)

Rabi Tawil, MD (Director, MSG Coordination Center, University of Rochester Medical Center)

Mazen Dimachkie, MD (Treasurer - University of Kansas Medical Center)

Thank you all.

Finally, the meeting this year, and every year, cannot happen without the extraordinary administrative work of Liz Paulk who serves as our MSG Administrative Director. Liz is a hands-on, detail-oriented individual who makes sure this meeting will be a positive event for all of us. She is one of the most optimistic, competent, and fun individuals I know and I am so glad we have her helping us to advance the agenda of the MSG: to be the premier neuromuscular clinical and translational research organization. THANK YOU, Liz!!

Rick 